\title{
PUU JAAGUPI PAJATUSED
}

\author{
MALL HIIEMÄE
}

$\mathrm{K}$ äesolev artikkel jätkab reaalelu seikadel ja sündmustel rajanevate humoristliku kallakuga narratiivide vaatlust (vrd Hiiemäe 2014). Tähelepanu keskmes on luiskelugude vestja Jaagup Puu (1879-1964) ning temalt talletatud jutupärand Eesti Rahvaluule Arhiivis. „Tema puhub nii, et on puhutud," iseloomustas Jaagupi - suure valetaja - talenti tema kaasaegne Hugo Klammer (EKRK I 31, 1134 (19c) < Viru-Jaagupi khk (1960)). Järgnevas püüan selgitada, miks ja kuidas pälvis jutustaja kogukonna tunnustuse ajastul, mil klassikaliste, rahvusvahelise levikuga valetamisjuttude aeg oli juba ümber saanud.

\section{Valetamisjuttudest rahvajuturegistrites}

Valetamisel ja petmisel on inimestevahelistes suhetes oluline koht. ${ }^{1}$ Naljandites ja muinasjuttudes kannab see enamasti omakasupüüdlikku eesmärki: oskuslik valetamine toob edu. Ekstreemsete elualade esindajad - tuletõrjujad, sõjamehed, korrakaitsetöötajad jt - võivad tõsielusündmusi vahendada humoristlikus laadis („must huumor”) oma psüühilise pinge maandamise eesmärgil (vrd parameedikute jutustustega oma kogetust, Tangherlini 2000: 48 jj). Fantaasiavale näib olevat sootuks teistsuguse funktsiooniga.

Rahvusvahelises jutukataloogis $\mathrm{ATU}^{2}$ esindatud valetamisjuttudele on omane liialdus kuni absurdini välja. Münchhauseni lood olid tuntud enamjaolt Põhja- ja Kesk-Euroopas ning Ameerikas. Nii Türgi sõja luiskelood kui ka jahimehejutud hõlpsasti saadud jahisaagist levisid Münchhauseni lugude nime all Eestis alates XIX sajandi keskpaigast. ${ }^{3}$

Väljapaistvaid valetajaid ning luiskelugude populaarseid prototüüpe teatakse kõigis maailmajagudes. Ka on hüperboolset liialdust kasutatud folklooris väga laialdaselt. Kaugeltki kõik tõsiloona välja pakutud fantaasiajuttude tegelased, nt Ameerikas farmerid, kauboid, metsatöölised, kalapüüdjad, paadimehed jts, ei kuulu ise tunnustatud jutuvestjate hulka, vaid on väljapaistvad oma tegevusalal või mingi erakordse omaduse poolest (vt Brown 1989).

${ }^{1}$ Psühhoanalüütilisest vaatenurgast on valetamise olemust põhjalikult analüüsinud Charles V. Ford (1996).

${ }^{2}$ Lühend ATU märgib koondkataloogi, mille aluseks on Antti Aarne (Aa) ja Stith Thompsoni (AT) juturegister täiendatuna Hans-Jörg Utheri poolt (ATU). Valetamisjuttude hulka (ingl tall tales, ATU 1875-1999) kuuluvad ka Münchhauseni lood (ATU 1889) ja selle arvukad redaktsioonid. Eesti folkloristidest on rahvajuturegistrite tüpoloogilist struktuuri võrdlevalt kommenteerinud Arvo Krikmann (2003).

${ }^{3}$ Parun Karl Friedrich Hieronymus von Münchhauseni (1720-1797) elukäik oli seotud Dunte mõisaga Lätimaal. Ta võttis osa Vene-Türgi sõjast ning ülendati vapruse eest leitnandiks. Karismaatilise isikuna, innuka jahimehena ning hea jutuvestjana sai ta maailma parima valetaja sümboliks. 
Suurustlevate lugude juurde kuulub ka fantaseerimine dimensioonidega (vrd ATU 1960-1968). ${ }^{4}$

Ajaloolise isiku parun Münchhauseniga seotud valetamislood on leidnud tee rahvajutukataloogidesse seetõttu, et neis kasutatakse paljude rahvaste folklooris tuntud süžeid. ${ }^{5}$ Kitsa levikuga isikujuttude tunnustamine folkloorina ning kogumine mäluasutustesse leidis seevastu rohelise tee alles XX sajandi teisel poolel seoses folkloori mõiste avardumisega ning ühtlasi uurimismetodoloogia muutumisega. ${ }^{6}$ Eesti folkloristikas toimus üleminek kultuuriantropoloogilisele uurimissuunale 1990. aastatel, põhjust on nimetada veel eluloouurimise ja pärimusliku ajaloo valdkonda (vt Jaago 2003; Kõresaar 2003). Muutusid ka kogumisideoloogiad. Välitööde eesmärgiks sai folkloorinähtuste status quo frontaalse fikseerimise asemel keskendumine pärimusprotsessi uurimuslikule jälgimisele. Rahvusvahelises folkloristikas pakkus isikujuttude kuulumine folkloori hulka aktuaalset arutlusainet eriti 1970. aastatel (Clements 1980). Näiteks, kui kultuurimiljöö on uurijale võõras, on narratiivi tüpoloogilise kuuluvuse määratlemine raskendatud (Clements 1980: 108-109).

\section{Puu Jaagup rahvaluulekogujate vaateväljas}

1960. aasta juunis võis 81-aastane Jaagup jutuhuviliste saabumise üle rõõmustada ning oma pajatustesse pandud elukäigu katkematu vooluna Tartu ülikooli rahvaluuletudengite ekspeditsioonist osavõtjaile ette kanda. „Kas võib leida paremat näidet egomorfismist!" kirjutab ajalehesõnumis oma välitöömuljetest üliõpilane Paul-Eerik Rummo (1960). „Niisugust head fabuleerimisoskust, lennukat fantaasiat ja ebatavalist improviseerimist võib harva kohata!" (Rummo 1960.) Oma luiskelugudega pälvis minategelane tema repertuaari talletajate hinnangus tunnustust isegi rohkem kui külarahva seas. ${ }^{7}$ Noorte jutuhuviliste tähelepanust innustatuna andis eakas jututaat endast parima, pühendades võõra kuulaja staatuses intervjueerijad oma eluloojutustuse üksikasjadesse. ${ }^{8}$ Ivi Hinn annab oma kogumispäevikus Jaagupile superlatiivse hinnangu: „Tõesti tore jutustaja, kõige ehtsam, keda ma kunagi näinud olen. [---] Haruldaselt väljendusrikas kõne, julged võrdlused ja „paraja tõega” jutud. Ja kuidas ta veel hoogu sattus. Silmad lausa särasid ja kogu tema olemus näis jutule kaasa elavat. Pole aluseta rahva hulgas tuntud ütlus: „See on Puu Jaagupi jutt"” (EKRK I 31, 222/9, Viru-Jaagupi khk (1960)).

\footnotetext{
${ }^{4}$ Eesti folkloristikas on hiiu- ja vägilasmuistendite suurusehüperboole nimetatud proportsioonifantaasiateks, kuid nalja mõistesse need ei kuulu (vt HVM I: 40-41).

${ }^{5}$ Parun Münchhausen on siin koondkuju, tema lugudeks on nimetatud ka muid jahimehejutte ja kalameeste kiidulugusid erakordsest saagist.

${ }^{6}$ Z̆anri hägustumise problemaatika ning uued suunavõtud olid rahvusvahelise jutuuurijate seltsi (ISFNR) 1974. aasta kongressi põhiteemaks (žanri mõiste muutumist vt Ben-Amos 1976). Tähelepanukeskmesse nihkus informant kui traditsiooni kandja, pärimuskollektiiv, teksti asemel ja kõrval kontekst (Honko 1998: 56-66).

${ }^{7}$ Puu Jaagupi pajatusi panid kirja Ene-Reet Ennuse ja Ivi Hinn, teise tandemina külastasid Jaagupit korduvalt Peet Lepik ja Paul-Eerik Rummo.

${ }^{8}$ Mõistet võõras kuulaja olen kasutanud juhtudel, kui informant kohandab oma repertuaari kuuluvat narratiivi mittekohalikule küsitlejale (Hiiemäe 2008: 16). Oma tavalise kuulajaskonna seas poleks Jaagup sedavõrd suurt efekti saavutanud. Mõistet spontaanne jutustamine väljaspool intervjuusituatsiooni on esile toonud Annikki Kaivola-Bregenhøj (1996: 52-54).
} 
Ka üliõpilaste regilaulu-uurijast juhendaja Udo Kolk on Puu Jaagupit tunnustanud kui erakordse fabuleerimisande ja -oskusega taati (Kolk 1960). Ilmnevad ajastuomastest folklooriteooriatest lähtuvad kõhklused autorsuse ja pärimuse leviku ulatuse suhtes: „Kuigi Puu Jaagupi juttude näol pole meil tegemist niipalju rahvatraditsiooniga kui üksikisiku erakordse fantaasiatoodanguga, võime nentida, et paljud tema motiivid on muutunud juba folklooriks. Neid antakse edasi suust suhu" (Rummo 1960). Kirjutiste autorid on silmas pidanud Eduard Laugaste kontseptsiooni folkloori elu faasilisusest. Esimene faas märgib rahvaluuleteose aktiivset kasutust, teine selle taandumist traditsioonist ja kolmandas faasis on rahvaluuleteos säilinud ainult kirjasõnas (Laugaste 1965: 54). Mõte, et folklooriteose esimesele faasile - n-ö suust suhu kandumise faasile - eelneks tekkefaas kui folklooriprotsessi osa, oli toonases eesti folkloristikateoorias võõras ja käsitamatu. ${ }^{9}$ Nähtavasti seetõttu ongi Peet Lepik ja Paul-Eerik Rummo hoolega jälginud Puu Jaagupi isikujuttude teadmist teiste külaelanike seas ning Jaagupilt uurinud samuti tema üldist folklooritundmist. Jutustajate kättejuhatamisel olid muuhulgas abiks ka ViruJaagupi kooli õpetajad.

Kõige püsivamalt - enam kui veerandsaja aasta jooksul - tegeles Puu Jaagupi pajatuste kirjapanemisega Viru-Jaagupi pastor Madis Oviir. ${ }^{10}$ Suure osa lugudest kuulis ta Jaagupilt endalt. Peagi, aastatel 1967-1989, hakkas ta rahvaluulearhiivi korrespondendina neid ka Tartusse kirjandusmuuseumile saatma. Nii nagu Jaagupit õhutas jutustama ülikooli esindajate ning pastori tähelepanu, nii innustas Oviiri mäluasutusele kaastööd tegema hinnatud kodu-uurija staatus. Seda fenomeni on esile tõstnud Janika Oras, kes nendib, et traditsiooni kandjale „oli oluline folkloristide ja väljastpoolt tulnud, prestiižse eluala esindajate tähelepanu. See andis kindlasti võimaluse oma positsiooni kogukonnas tõsta" (Oras 2005: 122).

Oviir tavatses rahvapärimust küsida teda kiriku kantseleis külastavatelt koguduse liikmetelt, algatas vestlust koosviibimistel (nt sünnipäevapeol või peielauas) ning kas või bussipeatuses bussi oodates, jättis kuuldu meelde ning kirjutas pärast üles, lisades kuupäeva. Saadetises pealkirjaga „Veel Puu Jaagupi jutte nende meeste suust, kes seni pole mulle veel rääkinud” kirjutab ta oma tähelepanekust: „Huvitav on see asjaolu, et Jaagupi jutud ühe ja teise suust kuulduna hakkavad varieeruma, mõnel jääb midagi ära, teine on pannud juurde seda, mida Jaagup ise võib-olla üldse ei ütelnud, aga surmkindlalt peab seda Jaagupi omaks rääkija" (RKM II 314, $320<$ Viru-Jaagupi khk (1975)).

On ilmne, et vestluses oma hingekarjasega jäid koguduse liikmed väljaütlemistes vaoshoituks ning pikantsemaid lugusid võidi koguduse kantseleis lausa vältida. Küllap hoidus selliseid rahvaluulearhiivile saatmast ka Oviir ise. Igatahes on Puu Jaagup oma juttude ja lauludegi sõnakasutuses end tundnud kahe uudistava tudengipoisi - Rummo ja Lepiku - seltskonnas üsna vabalt. Materjalikogumi võrdleval ülevaatamisel jääb mulje, et enesetsensuur

9 Tekkefaasi mõiste lisamisele faasilisuse teooriasse 1967. aastal (vt Proodel-Hiiemäe 1971: 112-113) sai osaks terav kriitika, senine geograafilis-ajaloolise meetodi sugemetega liigendus - 1) aktiivse kasutamise faas, 2) mälufaas, 3) unustamise faas - jäi püsima (vt Laugaste 1986: 57).

${ }^{10}$ Läänemaalt pärit Madis Oviir (1908-1999) asus usuteadust õppima pärast vabanemist 1956. aastal sunnitöölt Kolõma kullakaevanduses jm; teenis Viru-Jaagupi kogudust aastatel 1960-1994 (Pulver 2000). 
pole toiminud teistegi informantide puhul, kui küsitleja rollis olid need kaks noormeest, ning et ka Jaagupi lugudes polnud skatoloogiline aines võõras. ${ }^{11}$

Kirikuõpetajana oli Oviiril hõlpus teha väljavõtteid koguduse meetrikaraamatust. Tänu Jaagup Puu ja tema naise Anna täpsetele elulooandmetele on võimalik paremini mõista Jaagupi eluloojutustuse rõhuasetusi ja faktikasutust. Kogukonna liikmena äratas Oviir seltskonnas tähelepanu ka omapoolsete lugude jutustamisega. „Oviir oli eraelus huumorimeelega inimene, kes pani kirja anekdoote ja mõttevälgatusi," kirjutab tema iseloomustuseks Andres Pulver (2000: 164).

ERA välitööd Viru-Jaagupis toimusid 1984. aasta kevadsuvel. Jaagup Puu surmast oli siis möödas 20 aastat. Tema lugusid mäletati päris hästi, kuid osasaamist säravast esitusest Jaagupi kunagised kaaskondsed eriti ei rõhutanud, pigem konstateeriti, et „temal olid vigurijutud”. Mõned informantidest, sh Jaagupi lähinaabrid ja temaga tööl kokku puutunud isikud, meenutasid, et on Jaagupi jutustamisoskust juba noorpõlves tähele pannud.

Asunud Jaagupi jutupärandiga tutvuma, tundsin huvi, kas XXI sajandil tema luiskelugusid kohapealse rahva seas veel räägitakse. Sain vastuse: „Praeguseks on Puu Jaagup üsna unustusse jäänud. Neid, kes teda tundsid, on vähe järele jäänud ja nad on vanaks jäänud. Tema tollane naaber, kes samas praegugi elab, meenutas hiljuti veel üht Jaagupi lugu" (EFA I 177, 1 (1) $<$ Viru- Jaagupi khk < Võhu k - Anu Soon (2015)). Niisiis on Jaagupi isikuga seotud lugude eluea mõõduks folklooriprotsessis ligikaudu sada aastat. Lauri Honko (1998: 67-70) periodiseeringu järgi kuulub siia pärimusteadlikkuse sünd (teisisõnu: tekkefaas) ning pärimuse identifitseerimine väljastpoolt koos selle talletamisega (vastab esimesele faasile). ${ }^{12}$ Edasine etapp oleks Laugaste sõnutsi „unustamise faas, kus teksti rahva mälus enam ei leidu (peale mõne juhusliku fragmendi), on aga varasemais kirjapanekuis" (Laugaste 1986: 57). Honko käsitluses aga järgneb sellele „folkloori teine elu”, mil „pärimusprotsessist lahti rebitud ja talletatud aines satub jälle ringlusse" (Honko 1998: 77). ${ }^{13}$

\section{Näide Puu Jaagupi eluloojutustusest}

Naisevõtulugu võib pidada Jaagupi enesepresentatsiooni oluliseks abivahendiks. Tema suust kuulduna on see üsna pikk ja detailirohke. Eelisesitajaks peeti peategelase vanaduspäevilgi teda ennast. Tutvustatav tekstivariant pärineb Madis Oviiri saadetisest rahvaluulearhiivile. Ruumi kokkuhoiu eesmärgil toon esile sisulise kandvusega tekstilõike.

\footnotetext{
${ }^{11}$ Huumoriuurijate käsitlustes on skatoloogilist ainestikku loetud seksuaalhuumori juurde kuuluvaks (vt Gruner 1997, ptk „Sexual, sexist and scatological humor”, lk 107-129). Jaagup rõhutab enda maskuliinsust ja teda „kosivate” naiste innukust ebatsensuursel viisil, kuid otseselt seksuaalhuumorile ja roppustele tema lood ei keskendu.

${ }^{12}$ Kohaliku levikuga isiku- ja olustikujuttude eluea piiriks näibki traditsioonikandjate põlvkonna vahetumise tõttu olevat maksimaalselt sada aastat.

13 1990. aastal ilmus „Folkloreprosessi” soome keeles ja 1991. aastal teose tõlge inglise keelde (Honko 1992: 237).
} 
Siis aga mul oli kord tarvis Tallinna minna. Läksin jala Rakveresse, seal istusin rongi peale - esimest korda sõitsin rongiga - tead, vedur tossutab ees ja vagunid üksteise järele ikka veerevad Tallinna poole. Vaata aknast välja ja näed, kuidas tilevonipostid mööda kihutavad, puud ja mets ka. Paari-kolme tunni järele olingi Tallinnas. Oli õhtune aeg ja hakkasin oma sugulaste poole minema Liivalaia tänavale. Aga ega ma teadnud sugugi, kus see Liivalaia tänav on. Mul eesti keel suus ja et oli Eesti aeg sel ajal, siis sain eesti keelega igal pool läbi. Ja nõnda juhatati mind Liivalaia tänavale, et vaata, papi, see on Liivalaia tänav, seda mööda mine. Ja ma läksingi. Number oli mul teada ja igal majal oli oma number. Oma arvates hakkasin juba õige numbri lähedale jõudma, kui äkki märkan, et ühe hoovivärava juures nutab üks noor naisterahvas haledalt, ise hoiab valget taskurätikut näo ees. Et mul üldse naisterahvaste vastu üks hale ja helde süda on, siis läksin ma nutja juurde ja küsisin: „Ütle mulle, noor inimene, miks sa nutad õhtusel ajal siin hoovivärava juures. On sulle keegi haiget teinud või on süda rahutu ja raske?"

Noor naisterahvas tõstis korraks oma nutused silmad ülesse minu poole, vaatas mulle hetke silmi ja ütles siis läbi nutu: „Nutan sellepärast, et tahaks mehele minna, aga näe, ei ole võtjat! Oh, küll tahaks mehele minna!" Ja hakkab sealjuures nii haledalt nuuksuma ja südantlõhestavalt nutma, et mul hakkas üpris hale meel ja südamesse tuli kaastundmus selle õnnetu naisterahva vastu, kes tahab mehele minna, aga näe, võtjat ei ole ja see paneb nutma.

[Puu Jaagup kirjeldab oma sisemist arutlust ja jõuab otsusele. $-M$. $H$.]

Ja kas pole see naisterahvas mulle nagu taevaingli poolt seatud ja saadetud. Ja kohe ma mõtlesin nii, et see ehk ongi see minu õige naine. Kogusin juba jõudu ja julgust, et küsida nutjalt, kas tema tahab minule tulla naiseks, ennem aga tahtsin ta nägu näha, et kas ta on ka ilus ja kena inimene. Ütlesin siis: „Vaata korraks minu otsa ja näita, mis nägu sa oled?”

Naisterahvas vaatas mu otsa ja ma nägin tema nägu. Kena noor inimene, siniste silmade ja mustade kulmudega. Niisugust võib võtta küll. Nii otsustasin oma südames ja ütlesin siis: „Kas sina, noor inimene, ei taha minule naiseks tulla? Su mured oleksid kadunud ja ega ma siis viimane poiss ka ei ole."

[Pärast mõningaid kõhklusi ja kinnitusi on otsus tehtud. $-M$. H.]

Olime mõlemad Tallinnas. Nüüd oli vaja juhust kasutada, et laulatuse riided - asjad, sõrmused ja muud ära osta. Et mul raha oli küll, siis ostsin ma omale laulatuse ülikonna, Annale ja omale sõrmused, Annale kõige kallimast siidist ja pitsist laulatusekleidi riide ja kõik muu nagu peab. Kui olime kõik ära ostnud, siis küsis äkki mu pruut: „Kuule, mis su nimi on?” „Jaagup, ikka Jaagup!”

„Noh, aga liignimi?”

„Puu, Puu ikka. Noh, saa aru, Puu on mu liignimi ja Jaagup on mu eesnimi."

„Pisut võõras nimi,” arvas pruut, „aga eks sellega kord ka ära harju.”

„Aga sinu nimi?” küsib Jaagup.

„Minu nimi on Anna. [Anna räägib enda päritolust, nimetab sünniaasta. - M. H.] Ja siiasaadik on mulle aastaid kogunenud juba 46. Aga ega see ühe noore naisterahva kohta ju palju pole." 
[Abiellujad lähevad Viru-Jaagupi pastori juurde. $-M . H$. ]

Pastor vaatas Anna otsa, siis minu otsa ja küsis siis: „Ütle mulle, armas Jaagup, kust sa omale nii ilusa naise said?"

„Kust mujalt, kui ikka Tallinnast, ikka Tallinnast, armas pastorihärra, ei ilusamaid naisi pole kusagil kui Tallinnas."

[Selgub, et laulatus toimub pruudi elukoha kirikus. - M. H.]

RKM II 350, 193/203 (1-4) < Viru-Jaagupi khk - M. Oviir < Jaagup Puu, arhiivile saadetud 1980

Eraldi lugudes on Jaagup seletanud, miks ta eelistas vallalise seisust, kuigi tal oli palju pruute (24, teise variandi järgi 77 ). Ilmselt oli vallalisus talle probleemiks, oma hingekarjasele on ta sellest rääkinud usalduslikus vestluses, mis suurustlevale eneseeksponeerimisele ei pretendeeri. Tallinna sõidu muljed on tema naisevõtuloos juhuslik kõrvalepõige, tüüpiliselt algab süžee kohtumisega Liivalaia tänaval, kusjuures sugulaste külastust ei mainita. Seeeest dialoog nutva naisterahvaga on obligatoorne. Pulmarõivaste hankimine võib kuuluda ka tsüklisse Jaagupi majanduslikust võimekusest (laulatusülikonna riie ostetakse Lätimaalt, väärt rätsep leitakse Leedust).

Ühe-episoodiline lugu Jaagupi naise Ańna (palataliseeritult olevat nimi veel kenamalt kõlanud) ilust on kogukonnas kauemini populaarsena püsinud kui Liivalaia tänava kohtumise lugu. Varianditi kordub küsimus Jaagupile: „Kust sa nii ilusa ja noore naise said?” ja vastus, et Tallinnast, või hoopiski Narvast. Küsijaiks on prestiižikad isikud, kirikhärrad ning Küti parun Stackelberg, Jaagupi hea tuttav.

Järgmises jutuvariandis on olustikulised reaalsusele apelleerivad detailid lausa kõrvale jäetud. Jaagup teeb naisevõtmisloos kõrvalepõike:

[---] Isegi see vana ja vali praost pani tähele ja kiitis Anna ilu. Mis rääkida siis veel teistest! Oli sihukesi mehi, kes mulle ütlesid: „Võta see kakskümmend viis rubla ja lase ma vaatan korrakski sinu ilusat Annat.”

Ega mul polnud rahast puudu. Igaüks tahtis Annat näha, ikka raha näpuvahel - las ma korrakski vaatan su naist. Ja ma lubasin. Mis sa ikka keelad. [---]

RKM I 11, 86 < Viru-Jaagupi - M. Oviir < Jaagup Puu, 1963, arhiivile saadetud 1967

Jutuvestja kui traditsioonikandja staatust saab hinnata välitööde käigus, tehes seda otsekontaktis külakogukonnaga, rõhutab Anna-Leena Siikala Soome folkloristide 1969.-1970. aastate ühisekspeditsioonidel kogetule toetudes ning toob näiteid jutustaja eluloolise ainestiku kasutamisest jutustajaisiksuse positsiooni määratlemisel (Siikala 1990: 125-136). Puu Jaagupi ja tema ilusa naise kohta ei jäänud kõnekas kommentaar Viru-Jaagupist u 7 km kaugusel Võhu külas kuulmata:

Et parun pidand tõlla kinni, et: „Kust sa, Jaagup, selle ilusa naise oled saanud?" Aga tegelikult ta ilus pole old.

RKM II 370, 100/1 < Ellen Soon, s 1921 (1984) 
Lisada võib teisegi loo, mille jutustaja nendib, et jutte tekib juurde, Jaagup ise võib-olla mõnda ei teagi. Nimelt oli Jaagup Annale meeleheaks jalgratta ostnud ja ise sellega turbarabas tööl käinud, sest raske kehaga Anna ratta pealegi ei istunud.

EKRK I 32, 375 (1) < Viru-Jaagupi khk - P. Lepik ja P.-E. Rummo < Heino Vaasma, 36 a (1960)

\section{Eluloojuhtumuste kasutamine jutuloomes}

Anna-Leena Siikala (1990: 146-159) esitatud tüpoloogias kuuluks Jaagup Puu viie jutustajatüübi seas kõige esimesse, aktiivsete jutustajate ehk A-tüüpi, nagu on Antti Rintala (snd 1900) ning Jalmari Peltomäki (snd 1880). Mõlemad on maamehed, Rintala tegeleb puidu ülesostmisega ja Peltomäki on külasepp (Siikala 1990: 138). A-tüüpi kuulub ka tislerist jutuvestja Juho Oksanen (snd 1885, vt Kaivola-Bregenhøj 1996: 41-47). Kuid ükski neist, ei Rintala, Peltomäki ega Oksanen ei ole oma isikujuttudes voli andnud fantaasiale, nagu seda on teinud Jaagup Puu. Selleks et veenduda, kas ei tulene Jaagupi pajatuste suunitlus tema sotsiaalsest staatusest, jälgisin, kuidas tema elukäiku on kirjeldanud kogukonna liikmed ja millise varjundiga on nende arusaamades hinnang „suur valetaja”. Nagu mainitud, oli pastorist rahvaluulekoguja suhtumine Jaagupisse empaatiline ja mõistev, tema lugusid esmakordselt kuulanud folkloristikatudengite ja nende juhendaja hinnang aga ülivõrdeline. Jaagup ise ütleb neile oma jutukuse kohta: „Mina olen suure jutupläraga. Mitu päeva jahvatasin rahvaga" (EKRK I 31, 264 (22) < Viru-Jaagupi khk (1960)).

Oma biograafiat on Jaagup üsna asjalikult tutvustanud üliõpilastele ja samuti kirikuõpetajale. Andmeid Jaagupi töödest ja toimetustest, majapidamisest, kodusest elust jne on andnud samuti ümberkaudsete külade elanikud. Külade arv, kust Jaagupi pajatusi rahvaluulearhiivi on talletatud, ulatub üle 15 , informantide arv on poolesaja ringis. ${ }^{14}$

Jaagup Puu sündis 1879. aastal Viru-Jaagupi kihelkonnas Voore külas rendikoha pidaja pojana, peres oli kuus last. Jaagup käis kolm talve külakoolis, oli Küti mõisa paruni Kupna karjamõisas juba poisikesena karjaseks ja hiljem ka laudatööliseks, tegi põllul hooajatöid, lõikas metsa, ostis kokku ja müüs edasi talusaadusi. Pärast isa surma 1902. aastal (ema suri 1927. a) jäi Jaagup 23-aastaselt suure pere hooldajaks ja toitjaks. Jaagup olla kurtnud, et kui ta „on needitud kettidega lehmade külge ja ei saa kuhugi minna, siis võib jääda tegemata ka see kõige tähtsam ja meesterahvale üks vajalikum tegu - naisevõtmine" (RKM II 298, 104/5 - M. Oviir < Hugo Nõlve, 1973). Kuigi vanemad soovitasid noormehel pere luua, jäi see kauaks unarule. Jaagupi enesehinnangule mõjus positiivselt Küti valla turbatööliste ühingu poolt pakutud töödejuhataja koht. Seda pidas ta 48 aastat ning tundis end ametniku ja ettevõtja - „turbatöösturi” - seisuses hästi.

Need Jaagupi elukäigu asjaolud aitavad mõista, miks abieluseisusse astumine talle nii tähtis oli. Anna-Marie Toomeliga abiellus ta 52-aastasena. Lapsi neil polnud. Koos Annaga peeti lehma ja kanu, valmis sai väike maja Viru-Jaagupi alevis. Majapidamisest jutustades mainis Jaagup sageli oma

\footnotetext{
${ }^{14}$ Rühmavestlustes osalejaid pole Madis Oviir kirja pannud.
} 
head naist Annat ja Anna-poolset repliiki, et mis Jaagup teeb või ütleb, see on hästi öeldud ja õige, ning soovitas kahtlejail Annalt üle küsida.

Kõik siintoodu oli Jaagupi pajatuste tõsieluline aine ja raamistik, millele ta oma jutud üles ehitas, ning sama kehtib ka naisevõtuloo puhul. Külarahvas jutustas neid lugusid edasi, täiendas ja kommenteeris omalt poolt, kuid tegi ühtlasi Jaagupi biograafias korrektiive. Pajatusekangelasena oli Jaagup olnud mõisa aednik, loomatohter, „kanamuna agent”, sõjaväe kokk, Vihulas luua- ja vihavabriku direktor, Saaremaal kaubitseja, Venemaal tubakamüüja, kuid tegelikult mitte. Karjatalitajana saab Jaagup jagu kurjast pullist, kui loomal nt kõrva ümber sarve või saba ümber puu keerab, annab loomatohtrina lehmadele sünnitusabi, Saaremaal Annaga kanamune müües „sõidab munakoormaga ees, Anna rahataksoga järel”, Venemaal müüb tubakat läbi akna, sest kogu tuba on seda kaupa täis, jne. Turbaladumisel kurdab Jaagup, et käed on haiged, sest töölistele sai nii palju raha välja jagatud. Kulina veskile minekul hakanud hobune perutama ja ajanud viljakoorma ümber, aga Jaagup saanud hakkama, sest vankri juhtvits jäänud Jaagupi kõrva taha (või koguni keele taha) kinni.

Oma pajatustes on Jaagup aina kiire, osav, ilus, tugev, taiplik, ühtlasi varakas, ja tema majapidamine edeneb. Olgu lehma ostmine ja toitmine, sea nuumamine, kanakasvatus, aiapidamine - oskusliku teotsemise tõestuseks sobib kõigest jutustada ja teemasid jätkub. Populaarsemate hulgas on lood Puu Jaagupi lehmast ja kanadest. Jutt lehma ostmisest algab aruteluga, et tuleks lehm osta, kuid kust leida sobivat. Ostetakse 30-40 km kauguselt Tapa laadalt suur, kuigi lahja lehm, kellele head-paremat söödetakse. Kevadeks lehm kosub: „läikis ja lõkendas. Silmavaadegi oli rõõmus.” Kuid lehm ei mahu enam laudast välja. Puutöömees teeb ukseava laiemaks ja kõrgemaks. See, kes sügisel nende lehma üle naeris, imestab nüüd: „Sajast puudast pole palju puudu." Kõige efektsemaks on peetud asitõendeid lehma erakordse piimaanni kohta: „Jaagup lüpsab ühelt poolt, Anna teiselt poolt”; „kokku 20 ämbritäit”; „piima saab vannitäis”. Pealegi on piima peal paks koor: „Läinud ommiku vaatama - kass uitand piima peal." Sellest kujutluspildist jääb väheks. Jaagupi väärt lehma piimale tuleb mõne jutuvariandi järgi nii paks koor peale, et Jaagup seal ööd ära magab või siis tantsivad mõlemad Annaga kaerajaani. Jaagupi põllul kasvab ka vili suureks. Võrdluseks on seesama suur lehm, kes vilja seest välja ei paista, aga kui redeliga katusele ronida, on ta sarved näha. Jaagupi luiskelugudes kasvavad ounad kaalikasuuruseks või on „nagu oinapead” või „poolest õunast sai täismees kõhu täis”; kartulimaal jääb sahatera kartuli taha kinni ja pajas paisuvad kartulid nii suureks, et neid vaid raudkangiga sealt kätte saab.

Puu Jaagupi jutuloome iseloomustamiseks sobib tsitaat Oskar Looritsalt liialduse kasutamise kohta: „Me armastame liialdada täiesti loomulikku, tõesti sündinut. Meie kuuleme midagi ja jutustame seda edasi, aga lisame meeleldi jutujatkuks juurde „soola”, „pipart” ja „vürtsi”, me ilustame ja ehime loo suurepärasemaks, läheme seejuures üsna hõlpsasti ja hoopis ise seda hoomamata tõeluse piirist üle" (Loorits 2000: 11).

Looritsa artiklis on kõne all suure jõuga isikud - vägilaste prototüübid, kes saavad tuntuks teiste inimeste juttudes ega pruugi ise jutuvestmisega välja paista. Puu Jaagup on nimelt jutupuhuja, kõhetu ja väikest kasvu, kehvades 
oludes kasvanud töömees, hiljem väikemaapidaja ja kolhoosnik, kelle sooviks on fantaasia kaudu osa saada ideaalmaailmast. „Juba lapsepõlvest pääle meie „mina” kannatab tõepoolest aina alamal-olu tundest ja loob otsekui selle kompensatsiooniks vähemalt fantaasiaski elavaid pilte oma üleolust ja suurusest, jõust ja vägevusest," kirjutab Loorits niisuguse enesekehtestamisvajaduse kohta (2000: 10). Huumori mõiste definitsioonide järgi on tegemist sotsiaalpsühholoogilise fenomeniga vastavalt Sigmund Freudi psühhoanalüütilisele seletusele pingete maandamise viiside kohta (Raskin 1985: 131-132; Gruner 1997: 11).

\section{Puu Jaagupi pajatuste struktuurist ja stiilist}

Jaagupi jutuloome-eeskujudest on rahvaluulearhiivis vähe andmeid, peamiselt mainitakse tema teemaeelistusi. Tundub, et tegemist oli andeka iseõppijaga. Usundilisi muistendeid oli ta kuulnud emalt. Ümbruskonnas leidus mitmeid jahimehejuttude vestjaid, ka oli üks tema sugulastest käinud VeneTürgi sõjas. Jaagupilt on kirjutatud ka lugusid Rakvere vembumehest ja pajatusetegelasest Tallikast. ${ }^{15}$ Jaagup ise vembumees polnud, tema oli vembumees vaid juttudes. Nii jutustajale kui ka kuulajaskonnale kujunes sobiv situatsioon ühistööl puhkepauside aegu.

Ma tegin ka Jaagupi juures tööd. Ega ma polnud üksinda, teisi oli ka. Töö raske ei olnud, ladusime lõigatud turvast, mehed lõikasid. Jaagup tahtis kangesti rääkida. Vahest hakkas lõuna ajal rääkima ja kui ta hoogu sattus, siis ei saanud pidama. Küll sealt siis tuli kõiksuguseid jutte, üks parem kui teine. Aga ega see kõik tõsi polnud. Jaagup valetas, nii et suu suitses. Aga mis meil sellest oli, muudkui kuulasime ja naersime: tunnitöö. Raha tuli ka istumise eest. Ja kui Jaagup nägi, et jutud on huvitavad ja sa kuulad, siis pani aina hoogu juurde!

RKM II 298, 107 < Viru-Jaagupi khk - M. Oviir < Helene Vainu (1973)

Eesti folkloristikas äratab varase kontekstiuurijana tähelepanu Richard Viidalepp, kelle töödes leidub hulgaliselt üldistusi jutustajate esitusviisist, narratiivi taotluslikust seostamisest konkreetsete oludega usutavuse tõestamiseks, aga ka laskumisest liialdustesse (vt Viidalepp 2004: 102-181). Jutustamine ei saa olla ühepoolne akt: „Ainult viljakas vaimses ühtsuses saavad toimuda tundidepikkune jutustamine ja kuulamine" (Viidalepp 2004: 120). Nii oli ka Jaagupi lugudega. Soodsa võimaluse puhul haaras ta osavalt kinni mingist mõttearendusest konversatsioonis. Tema lugudes on kõrvalepõikeid ja vahelekiilundeid, temaatiliselt sobivate episoodide kordamist. Nt jutustas ta Lepikule ja Rummole, kuidas naised end talle järjepanu kaasaks pakkuma tulid: õmbleja, kangur, pildimaaler, siis agendiproua Tartust. Kirjeldanud, kuidas neist vabaneda õnnestus, lisas ta lõpetuseks, kuidas tulnud oma paksu tütart pakkuma üks vanamees. Temale öelnud Jaagup: „Kui sa temast tahad

${ }^{15}$ 1998. aastal valiti Eduard Tallikas (1885-1954) XX sajandi viiekümne kõige vägevama Virumaaga seotud isiku hulka (Pulver 2000: 94-95). 
lahti saada, siis mine temaga Tartu või Tallinna, seal ostetakse neid vanu tüdrukuid kokku seebivabrikus 18 senti nael. Saad selle eest 25 senti naelast!" (EKRK I 32, 143 (4) < Viru-Jaagupi khk - P. Lepik ja P.-E. Rummo < Jaagup Puu (1960); järgneb oma naise leidmise lugu).

Jaagup on kasutanud ka sõnade kordamist loendina (vrd parallelism regilaulus; näide on eeltoodud tekstist): „Proua soovis kondrapulma, vabaabielu, registreerimist või laulatust." Kondrapulm tähendab siin kontrahiga (lepinguga) pulma, ent järgmises tekstis on kumulatiivse loendi kogumõju ilmselt olulisemgi kui üksiksõnade tähendus.

Ja-jahh, ma tean Puu Jaagupit küll. Oli üks jutumees, muud ei teinud, kui ajas lorijutte, noh, sihukesi võimatuid asju, mis ei saa kohe olla, ega tema peas oli neid küll.

Ühte juttu ma mäletan küll. See oli niisugune asi, et täma naisel olnud palju jakke. Noh, neid mis selga pannakse. Küll olnud neid Anna enda tehtud, ostetud, kingiks saadud, leitud, vahetatud ja neil olid oma nimed ka. Ja Jaagup ikka luges, et tema naisel olnd tikkjakk, sakkjakk, pitsjakk, lipsjakk, lappjakk, lakkjakk, sukkjakk, kikkjakk, pikkjakk. Peale nende oli Annal veel pulmajakk, varrujakk, matusejakk, laulatusejakk, tööjakk, ööjakk, surijakk ja mis neid veel oli... Neid jakkisi olnud Jaagupil nii palju, et ühte kappi polnud ära mahtunud, muist pannud kummuti sahtlisse ja muist viis õpetaja kätte hoiule.

RKM II 416, 166/7 (3) < Viru-Jaagupi khk - M. Oviir < Leida Mägi (1986)

Võrdluseks teistsuguse sisuga tekstinäide loendi kasutamisest - kas olustikujutt või luiskelugu?

Puu Jaagup olnud juba ammust aega vanapoiss. Teised küsinud, et ku'le Jaagup, mispärast sa naist ei võta. Jaagup vastanud: „Ei mul pole aega naist võtta, ma ehitan oma õdesid. Ühele õele muretsesin juba seitse jakki: sakkjakk, pikkjakk, suijakk, talijakk, saksajakk, hõbejakk ja kuldjakk. Teisele õele aga kuus kübarat: suimüts, talimüts, tuttmüts, huttmüts, raudmüts ja pärismüts. Kui nüüd õed nii toredasti on ehitatud, siis vaatan enesele naise ka."

RKM II 332, 153/4 (6) < Viru-Jaagupi khk - M. Oviir < Rudolf Klammer, 70 a (1977)

Ilmselt paelusid kuulajaid tõsielufaktide ja hüperboolse kujundikasutuse kontrast, ilmekad metafoorid, võrdlused ja epiteedid, piltlikustamine, situatsioonikoomika, rohke dialoog, retoorilised küsimused ja hüüatused, loodushäälte imiteerimine, žestid ja elav miimika. Jaagupi isikupärase jutustamisviisi juurde kuulus veel manipuleerimine võimendatud arvsuurustega, otsekui oleks tegemist täpsete andmetega: sõrmeveos tõmbab ta üles 25 leeripoissi. Küti mäel pähkleid korjates kaotab 38000 krooni raha, sünnipäevaks saab 22 (40) torti ja 22 (40) vesti. Kulina mõisahärral Babinil ütleb ta naisi olevat 18 ja lapsi 80. Ümbruskonnas tähendab määrang „Puu Jaagupi täpsusega” näilist täpsust. 


\section{Puu Jaagup ja tema ajastu}

Tänu Lepiku ja Rummo initsiatiivile ilmnes informantide küsitlemisel, et Jaagup jutustab samasuguse elamuslikkusega lugusid kohtumisest metsloomadega (karud, hundid, metskitsed, jänesed) või üleloomulike olenditega (vanapagan, kratt, ussikuningas, luupainaja). Memoraate on ta jutustanud sedavõrd usutavalt, enesekiituseta, et neid võiks pidada fantaasiavabadeks. Siin on meenutus kohtumisest ussikuningaga:

[---] Sie pole vale jutt! - Ümber puu oli. Aga tal oli nii tore punane ari kui kukel. Õhuke, aga tulipunane. Võtsin kepi, viskasin - poisikese asi, olin tattnina, - aga see kepikõps läks ussi vastu, just sinna kaela peale. Aga jäme oli - oh sa looja - nagu minu pintsakuvarrukas. [Tõstab käe üles, pintsak on tal seljas ja võtab sellest teise käega kinni.] Pia oli kole suur. Sie pulk läks tämale just kaela piale. Vaatan, mis nüid tuleb. Oh sa taevaisa! Ja siis akkas nii palju neid ussisid välja tulema. Kõrvu reas kõik tulid, vanu ja nuori. Süllalaiuselt. See vana völakas oli ies, pia oli püsti kui mu kepp [tõstab oma käepidemega kepi üles]. Mina akkasin karjuma. [---]

EKRK I 31, 270/1 (30) < Viru-Jaagupi khk - P. Lepik ja P.-E. Rummo < Jaagup Puu (1960)

Olukorra lahendas ussisõnu teadev mõisavalitseja. Võib arvata, et niisuguste kohtumiste tõesuses ei kaheldudki. Jaagupi poisipõlves ja samuti meheeas polnud muistendid ussikuningast, nõiaoskustega inimestest, krattidest, luupainajatest ning kodukäijatest veel kaugeltki usutavust kaotanud. Kuid mida arvata Jaagupi kuraasitamisest Münchhauseni lugude laadis: suudab kolme versta peale sääse ära näha; jookseb koerast kiiremini; võib „laulda alti, tenorit, tiiskanti"; tal on nii vana kell, et pendli vari on seina sisse augu kulutanud; Jaagupi ja Anna kanad munevad mitu muna päevas, kui neile hiina või veel parem vietnami riisi sööta; pumbakaevust tuleb ämbrisse kalu (variandid: soolasilku, papinaelu, kapsaid); külm lööb kirvesilma lõhki jne.

Jaagupi repertuaarist on jahimehejutte küll kirja pandud, ent ise ta jahi vastu huvi polevat tundnud. Selleks ajaks, mil tema lugusid talletama hakati, olid Eestis klassikalised valetamisjutud aktiivsest kasutusest juba taandunud. Jahisektsioonide liikmeid lausa noomiti: jahimehed olevat oma reputatsiooni rikkunud sellega, et kaunistavad lugusid väljamõeldistega. Nii tegevat hädavaresed, aeg oleks luiskamine lõpetada (Malt 1960: 24-25). Koos münchhausenlike äraleierdatud kiidulugude taandumisega leidis aset nende ümberkujundamine ja rõhuasetuste teisenemine (Proodel 1969: 11-13, 22-28). ${ }^{16}$

Üks Jaagupi meisterlikumaid fabuleeringuid, pikem kui naisevõtulugu, algab tervistavate saunavihtade valmistamisega. Vihula vihavabriku kuulsus kasvab, asjast saab kuulda keiser, „väike mees kasvu poolest, ei olnud just tugeva tervisega mees”. Nikolai II saadab Jaagupile kirja kohtumissooviga teel

\footnotetext{
${ }^{16}$ Aastatel 1967 ja 1971 intervjueeriti teisel pool maakera Texase osariigis Ed Belli, kes oma luiskelugudes jahi ja kalapüügi teemal on kasutanud samasuguseid stiilivõtteid. Temagi lugudes on ohtralt dialoogi, olustikulisi detaile, nimetatud on paiku ja isikuid, esile tõstetud dramaatilisi olukordi (vt Mullen 1976: 303-310). „Ühest küljest need luiskelood sobivad meie aega, aga teisest küljest nagu ei sobi ka, sest me kipume neid hindama oma ühiskonna kultuurinormide järgi," möönab Eda Kalmre Münchhauseni lugude XX-XXI sajandi reministsentsi kohta (Kalmre 2008: 85).
} 
Haapsalusse Rakvere raudteejaamas. Kulminatsiooniks on kohtumine punasest plüüsist vaibal, keiser kingib Jaagupile briljantide ja monogrammiga kuldkella (RKM II 407, 275/87 (4)). Madis Oviir on Jaagupilt kuuldu vormistanud raamjutustusena: Jaagup oli tulnud talle näitama 1927. aastal tehtud fotot, kus ta istub turbatööliste seas, haruldane kingitus väljasirutatud käes.

Kas teate, õpetaja, see uur, mis ma selle pildi peal käes hoian, pole harilik tasku-uur mitte. See on läbi puhtamast kullast, briljantidega kaunistatud, sisekaanel on monogramm. Teate, kelle oma? - Ei tea, seda ma juba tean ja kas te seda võitegi teada. Seal on Vene riigi isevalitseja ja majesteet Nikolai Teise enda monogramm. Tõesti, see on keisri oma. Ma olen seda uuri siin hoidnud sest saadik, kui silmatera. Kaasa võtan siis ja pistan vestitasku siis, kui mõned tähtsamad sündmused on, nagu varrud, pulmad, matused, või nagu selle pildi peal on. [---] See jääb näha ka tulevastele põlvedele, et nad näeksid, milline kange mees Puu Jaagup on olnud! Keisri enda kingitud kulduur vestitaskus.

„Kuidas sa selle uuri said?”

„Ah, kuidas sain. See on juba teine küsimus. See on pikk jutt, kui tahad kuulda, võin kõik täpipealt ära rääkida.”

„Tahan küll."

„Mul oli omal ajal Vihulas luua- ja vihavabrik. Seal ma tegin neid vagunite viisi ja saatsin neid paljudesse kohtadesse." [---]

RKM II 407, 275/87 (4) < Viru-Jaagupi khk - M. Oviir

Jutud keisri või kindrali tänust oma alamale kuuluvad Türgi sõja lugude tsüklisse. Tunnustuse oli saanud ka selliste lugude prototüüp von Münchhausen ise. Puu Jaagup on sõjakangelasteo lobedalt välja vahetanud ning oma aja ära elanud teemale „uue hingamise” andnud. Kuigi XX sajandi kultuurilises kontekstis oli fantaasiavalele rajatud narratiivi osatähtsus juba marginaalne, on kogukonna suhtumine valetamisnaljandite esitajasse üldiselt tunnustav (vrd Dorson 1964: 68). Ent ette tuli häirivatki. Kui Oviir esitas oma ämmale loo Jaagupi lehmast, keda talvel külmaga kaks nädalat lüpsmata peeti ja seejärel pesuvannitäie piima andis, olevat ämm ironiseerinud: „Seda juttu võivad ajada niisugused inimesed, kes lehmapidamisest mõhkugi ei tea" (RKM II 238, 115 (1973)). Kuna kuulaja valet huumorina ei tajunud, järgnes hoopis kriitika. ${ }^{17}$

Külaelanike repliigid 1984. aasta kogumisretke ajast (nt „Mis sest hullust rääkida! Ta oli kange luiskama”; „See oli natuke kerge mees old. Niisugune isemoodi tüüp oli” jne) viivad mõttele, kas ei arvatud Jaagupi valetamiskalduvust takkajärgi koguni vaimseks hälbeks. Tõepoolest, Soome kolleegid on veidi varasemast perioodist esile toonud sadakond külahullu, kellest Runsas-Jussi olla aina arvudega liialdanud ja Sliippari-Antti Vene keisrilt tänuks kuldkella saanud (Laaksonen jt 1990: 196, 199-200). Küllap oleks Puu Jaagupki XIX sajandi lõpukümnendite sotsiaalsetes oludes kogukonna ülalpeetavate veidrike kategooriasse arvatud, kuid ta suutis toime tulla, kuigi „tegelikult oli ikka üks kehvemaid”. Et Jaagup juba noorpõlves suur jutusõber oli, olevat mõned mehed, kel töö tegemist ootas, tema eest peitu läinud. Võib-olla said ühetaolise suunitlusega lood ka ülearu tuttavaks. Oviir kirjutab:

\footnotetext{
17 Äpardunud huumorist, põhjuseks kuulaja eelhäälestatuse puudumine, vt Laineste 2010: 655-656. Nähtus on tunnuslik virtuaalsetele suhtlusvõrgustikele.
} 
Kõnelesin 1969. aasta suvel Mõdrikus eluneva Puu Jaagupi õe Liisaga (perekonnanimi Oja). Tema teadis küll seda, et vend Jaagup oli suur jutumees, ja tõemeelega naljahammas, aga ütles nii: „Ah, see va Jaagup fantaseerib mis kole, ega see kõik pole tõsi, mis ta räägib. Ajas seda va lora, et häda kuulata."

RKM II 298, 114 < Viru-Jaagupi khk - M. Oviir < Liisa Oja (1973)

\section{Lõpetuseks}

Eesti XX sajandi folklooriprotsessis on Puu Jaagupi pajatused ilmekas näide tõsieluseikade ja fantaseeringute sümbioosist, ilma milleta poleks sellal valetamisjutud elavas jutuvestmistraditsioonis püsida saanud. Lauri Honko (1998: 77-78) sõnutsi ajendab pärimusteadlikkus folkloorile uue elu andmist, kuigi teises vormis ja teises kultuurikontekstis. Puu Jaagupi pajatustele „unustamise faasi" jäämine osaks ei saanud. 1985. aastal paigutati Madis Oviiri algatusel Viru-Jaagupi kalmistule mälestuskivi jutumehe Puu Jaagupi ja Anna eludaatumitega, 1989. aastal valmis õpetaja Mia Tikopi initsiatiivil käsikiri Jaagupi lugudest, 2001. aastal kirjutas kapelli liige Anu Soon laulumängu stsenaariumi, 2004. aasta jaagupipäeval (kihelkonnapäeval) ja veel Rakveres mihklilaada raames Rakvere muuseumi hoovis toimusid etendused ning 2007. aastal korraldati Viru-Jaagupi koolimajas teemaõhtu Puu Jaagupist rahvajututegelasena.

Artikli valmimist on toetanud Haridus- ja Teadusministeeriumi uurimisprojekt IUT22-4 „Folkloor kultuurilise kommunikatsiooni protsessis: ideoloogiad ja kogukonnad".

\section{Käsikirjalised allikad}

Eesti Rahvaluule Arhiivi kogud: EFA, EKRK, ERA, RKM.

\section{Kirjandus}

ATU = Hans-Jörg Uther 2004. The Types of International Folktales. A Classification and Bibliography, Based on the System of Antti Aarne and Stith Thompson. Part II: Tales of the Stupid Ogre, Anecdotes and Jokes, and Formale Tales. (FF Communications 285.) Helsinki: Academia Scientiarum Fennica.

B e n - A m o s, Dan 1976. The concepts of genre in folklore. - Folk Narrative Research. Some papers presented at the VI congress of the International Society for Folk Narrative Research. (Studia Fennica 20.) Helsinki: Finnish Literature Society, lk 30-43.

B r o w n, Carolyn 1989. The Tall Tale in American Folklore and Literature. Knoxville, Tennessee: University of Tennessee Press.

C l e m e n t s, William M. 1980. Personal narrative, the interview context, and the question of tradition. - Western Folklore, kd XXXIX, nr 2: published by the California Folklore Society, lk 106-112.

D o r s o n, Richard 1964. Buying the Wind. Regional Folklore in the United States. Chicago-London: The University of Chicago Press. 
F o r d, Charles V. 1996. Lies! Lies! Lies! The Psychology of Deceit. WashingtonLondon: American Psychiatric Press.

Gru n e r, Charles R. 1997. The Game of Humor. A Comprehensive Theory of Why We Laugh. New Brunswick-New Jersey: Transaction Publishers.

H i i e m ä e, Mall 2008. Jutuvestja kui isiksus. - M. Hiiemäe, Sõnajalg jaaniööl. (Eesti mõttelugu 73.) Tartu: Ilmamaa, lk 15-24.

H i i e m ä e, Mall 2014. Naljakatel eluseikadel rajanevad lood kogukonnapärimuses. - Keel ja Kirjandus, nr 11, lk 845-861.

H o n k o, Lauri Olavi 1992. Bibliography 1955-1991. - Folklore processed in honour of Lauri Honko on his $60^{\text {th }}$ Birthday $6^{\text {th }}$ March 1992. (Studia Fennica. Folkloristica I.) Toim Reimund Kvideland jt. Helsinki: Suomalaisen Kirjallisuuden Seura, lk 233-259.

H o n k o, Lauri 1998. Folklooriprotsess. - Mäetagused. Hüperajakiri, nr 6, lk 56-84. http://haldjas.folklore.ee/tagused

HVM I = Eduard Laugaste, Erna Normann (koost) 1959. Muistendid Kalevipojast. (Monumenta Estoniae Antiquae II.) Eesti muistendid. Hiiu- ja vägilasmuistendid I. Tartu Riiklik Ülikool, Eesti NSV Teaduste Akadeemia, Fr. R. Kreutzwaldi nimeline Kirjandusmuuseum: Eesti Riiklik Kirjastus.

J a a g o, Tiiu 2003. Pere- ja suguvõsalood pärimuses. 20. sajandi teine pool. Mälu kui kultuuritegur: etnoloogilisi perspektiive. Ethnological Perspektives on Memory. (Studia ethnologia Tartuensia 6.) Toim Ene Kõresaar, Terje Anepaio. Tartu: Tartu Ülikooli Kirjastus, lk 33-59.

Ka ivol a - B r e g e n h øj, Annikki 1996. Narrative and Narrating. Variation in Juho Oksanen's Storytelling. (FF Communications 261.) Helsinki: Academia Scientiarum Fennica.

K a l m r e, Eda 2008. Münchhauseni jutu retseptsioonist tänapäeval ehk milleks me neid vajame. - Kes kõlbab, seda kõneldakse. Pühendusteos Mall Hiiemäele. (Eesti Rahvaluule Arhiivi toimetused 25.) Koost Eda Kalmre, Ergo-Hart Västrik. Tartu: EKM Teaduskirjastus, lk 75-89.

Ko 1 k, Udo 1960. Rahvaluulekogujate ekspeditsioonist Viru-Jaagupisse. - Edasi 23. VII, nr 149, lk 3.

Kri k m a n n, Arvo 2003. Puändita naljandite struktuurist. - Keel ja Kirjandus, nr 3, lk 161-177.

K õ r e s a a r, Ene 2003. Eluloolisest käsitlusviisist Eesti kultuuriteadustes. - Pärimus ja tõlgendus. Artikleid folkloristika ja etnoloogia teooria, meetodite ning uurimispraktika alalt. Koost Tiiu Jaago. Tartu Ülikool, eesti ja võrdleva rahvaluule oppetool. Tartu: Tartu Ülikooli Kirjastus, lk 61-76.

L a a k s o n e n, Pekka, Pi e la, Ulla, L a h ti, Pirkko (toim) 1990. Satayksi originellia. - Hullun kirjoissa. Näkökulmia suomalaiseen külähulluuteen. (SKS toimituksia 508.) Toim Pekka Laaksonen, Ulla Piela, Pirkko Lahti. Helsinki: Suomalaisen Kirjallisuuden Seura, lk 110-214.

L a i n e s t e, Liisi 2010. Äpardunud huumor internetikommentaarides. - Keel ja Kirjandus, nr 8-9, lk 655-670.

L a u g a s t e, Eduard 1965. Loenguid eesti rahvaluule üldkursusest. Tartu Riiklik Ülikool, eesti kirjanduse ja rahvaluule kateeder. Tartu.

L a u g a s te, Eduard 1986. Eesti rahvaluule. Kolmas, parandatud ja täiendatud trükk. Tallinn: Valgus.

L o o r its, Oskar 2000. Meie, eestlased. (Eesti mõttelugu 35.) Koost Hando Runnel. Tartu: Ilmamaa, lk 9-45. 
M a l t, Hillar 1960. Kui kuulata jahimeeste juttu. - Abiks jahimehele. Tartu: VSÜ „Kalev” Tartu, Pärnu ja Tallinna jahindusklubid, lk 21-25.

$\mathrm{M} \mathrm{u} l 1$ e n, Patrick B. 1976. The tall tale style of a Texas raconteur. - Folk Narrative Research. Some papers presented at the VI congress of the International Society for Folk Narrative Research. (Studia Fennica 20.) Helsinki: Finnish Literature Society, lk 303-311.

O r a s, Janika 2005. Viie 20. sajandi naise regilaulumaailm. Arhiivitekstid, kogemused ja mälestused. (Eesti Rahvaluule Arhiivi toimetused 27.) Tartu: Eesti Kirjandusmuuseumi Teaduskirjastus.

P r o o d e l, Mall 1969. Üks jahimees läks metsa. Valimik rahvajutte jahist ja metsloomadest. Tallinn: Eesti Raamat.

Pro odel-Hi i e mä e, Mall 1971. Rahvajuttude kujunemisest Kodavere kihelkonnas. - Paar sammukest eesti kirjanduse uurimise teed. Uurimusi ja materjale VII. Tartu: Fr. R. Kreutzwaldi nimeline Kirjandusmuuseum, lk 101-122.

Pulver, Andres 2000. Madis Oviir. - Viru vägevad. Tallinn: VR Kirjastus, lk 164-165.

Raskin, Victor 1985. Semantic Mechanisms of Humor. Dordrecht-BostonLancaster: D. Reidel Publishing Company.

R u m m o, Paul-Eerik 1960. Mehest, kes on näinud ussikuningat. - Tartu Riiklik Ülikool 19. XII, nr 36, lk 4.

S i i k a l a, Anna-Leena 1990. Interpreting Oral Narrative. (FF Communications 245.) Helsinki: Academia Scientiarum Fennica.

T a ngherlini, Timothy R. 2000. Heroes and lies: Storytelling tactics among paramedics. - Folklore, kd 111, nr 8, lk 43-66.

V i i d a l e p p, Richard 2004. Eesti rahvajuttude laadist, funktsioonist ja jutustajatest. (Sator 4.) Tartu: Eesti Kirjandusmuuseumi rahvausundi töörühm.

\section{The tall tales told by Jaagup Puu}

Keywords: folklore process, humorous narrative, storytelling tradition, tall tale, true story

The subjects and style of the stories told by Jaagup Puu (1879-1964) are analysed. Jaagup's stories could be classified under tall tales like those in ATU 1875-1999. Jaagup used to narrate about his own life experiences, using exaggerations and fantasy bordering on the absurd. This socially poor and meagre-looking man would tell his stories, if possible, for two or three hours on end, emplotting the facts and events of his personal life, developing the story in great length, adding intermediate episodes, contaminations and comments. His stories are full of exaggerations, manipulation with numbers and dimensions, comical situations, abundant dialogue, similes, rhetorical questions and exclamations, gestures and miming. This was a masterful symbiosis of facts and fiction.

By the mid-20 2 th century fraudulent narratives had already receded from active story-telling as inopportune, being openly discouraged even from hunting and fishing stories. This is mainly why Jaagup's stories could not spread any too far in space or time. Nor did the stories have the social focus characteristic of jokes.

Mall Hiiemäe (b. 1937), PhD, Estonian Folklore Archives (Estonian Literary Museum), Senior Researcher, mall@folklore.ee 